Sains Malaysiana 47(7)(2018): 1599-1605

http://dx.doi.org/10.17576/jsm-2018-4707-31

\title{
Flow and Heat Transfer in a Nanofluid Thin Film over an Unsteady Stretching Sheet
}

(Aliran dan Pemindahan Haba dalam Filem Nipis Nanobendalir atas Kepingan Meregang Secara tak Mantap)

\author{
R.C. AZIZ, I. HASHIM* \& S. ABBASBANDY
}

\begin{abstract}
This study analyzes the heat transfer of a thin film flow on an unsteady stretching sheet in nanofluids. Three different types of nanoparticles are considered; copper $\mathrm{Cu}$, alumina $\mathrm{Al}_{2} \mathrm{O}_{3}$ and titania $\mathrm{TiO}$, with water as the base fluid. The governing equations are simplified using similarity transformations. The resulting coupled nonlinear differential equations are solved by the Homotopy Analysis Method (HAM). The analytical series solutions are presented and the numerical results obtained are tabulated. In particular, it shows that the heat transfer rate decreases when nanoparticles volume fraction increases.
\end{abstract}

Keywords: Heat transfer; nanofluids; thin film flow

\section{ABSTRAK}

Kajian ini menganalisis pemindahan haba bagi aliran filem nipis di atas kepingan meregang secara tak mantap dalam nanobendalir. Tiga jenis nanozarah berbeza telah dipertimbangkan; tembaga $\mathrm{Cu}$, alumina $\mathrm{Al}_{2} \mathrm{O}_{3}$ dan titania $\mathrm{TiO}_{2}$ dengan air sebagai bendalir asas. Persamaan menakluk dipermudahkan dengan menggunakan persamaan penukaran. Persamaan pembeza tidak linear berangkai yang terhasil diselesaikan melalui Kaedah Analisis Homotopi (KAH). Siri penyelesaian analitik ditunjukkan dan keputusan berangka yang diperoleh dijadualkan. Secara khususnya ditunjukkan bahawa kadar pemindahan haba menurun apabila isi padu pecahan nanozarah meningkat.

Kata kunci: Aliran filem nipis; nanobendalir; permindahan haba

\section{INTRODUCTION}

The study of a flow and heat transfer in a thin liquid film is often encountered in industrial and engineering applications. Such processes are wire and fiber coating, cooling of metallic plates, drawing of a polymer sheet, aerodynamic extrusion of plastic sheets and thinning of copper wires. Wang (1990) was the first to study the hydrodynamics of a flow in a thin liquid film driven by an unsteady stretching surface. His pioneering work was subsequently extended by Andersson et al. (2000) to include analysis of heat transfer. This study was later extended to the case of more general form of the prescribed temperature variation by Liu and Andersson (2008). Abel et al. (2009) investigated the combined effects of non-uniform heat source/sink and magnetic field on thin film flow and heat transfer over an unsteady stretching sheet. They found that increasing the non-uniform heat source/sink and magnetic field parameters has the effect of increasing the local Nusselt number. Vajravelu et al. (2012) studied the flow and heat transfer in a power-law liquid film on an unsteady porous stretching sheet in the presence of viscous dissipation and temperature-dependent thermal conductivity. In particular, they found that for all values of the power-law index, the dimensionless free surface temperature can be increased by the presence of viscous dissipation. The effects of slip, viscous dissipation and variable heat flux were considered by Megahed (2015) for the case of Casson fluid. It was shown that increasing the slip velocity parameter has the effect of decreasing the thin film thickness, the skin-friction coefficient and the local Nusselt number. Waheed (2016) studied thermal radiation effects on flow and heat transfer in an upper convected Maxwell liquid film on an unsteady stretching sheet embedded in a porous medium. Increasing the Darcy parameter and the Deborah number was found to decrease the velocity and the film thickness. Very recently, Dandapat et al. (2017) investigated analytically thin film flow of biviscosity liquid over an unsteady stretching sheet. They showed that the film thins quicker for bi-viscosity fluids as compared to Newtonian fluids.

Wang (2006) was probably the first to report analytical solutions of the exact same problem of Andersson et al. (2000) using the homotopy analysis method (HAM). The HAM is a general analytic method to obtain series solutions for various types of nonlinear equations (Aziz et al. 2012; Hayat et al. 2012; Liao 2004). Wang's (2006) model has been extended and analyzed using HAM by several researchers. For example, Wang's (2006) analysis was extended by Noor et al. (2010) to include the magnetic field and a more general surface temperature. The effects of viscous dissipation and a general surface temperature were taken into account in Wang's (2006) problem by Aziz and Hashim (2010). Noor and Hashim (2010) extended the model of Wang (2006) to include 
thermocapillary and magnetic field effects. The effects of internal heat generation and general surface temperature were considered by Aziz et al. (2011). They showed that the temperature-dependent parameter has no effect on the velocity, but exerts a big effect on the temperature.

In a parallel research stream, some interest has been given to the study of boundary layer flow of nanofluids. Choi (1995) introduced the term 'nanofluid' as a new class of fluids. Nanofluids are fluids containing nanoparticles (nanometer-sized particles of metals, oxides, carbides, nitrides or nanotubes). These fluids are engineered colloidal suspensions of nanoparticles in a base fluid. Several researchers have investigated the heat transfer characteristics of nanofluids (Abu-Nada \& Oztop 2009; Maiga et al. 2005; Tiwari \& Das 2007). Their results have shown that the presence of the nanoparticles in the fluids increases the thermal conductivity of the fluid and consequently enhances the heat transfer characteristics.

To the authors' best knowledge, very few studies have thus far been communicated with regard to thin film flow on an unsteady stretching sheet in nanofluids. Narayana and Sibanda (2012) were probably the first to extend the work of Liu and Andersson (2008) to the case of thin nanofluid film. They solved the transformed governing equations by the Runge-Kutta-Fehlberg and NewtonRaphson methods. Later, Xu et al. (2013) extended the problem first formulated by Wang (2006) to the case of thin nanofluid film. However, the results presented using HAM were for the value of the Prandtl number which is not suitable for water-based nanofluids. Recently, Maity et al. (2016) investigated thermocapillary effect on flow and heat transfer of thin nanoliquid film. Unlike all the works mentioned, they considered the full Navier-Stokes quations. In this work, we investigate the flow and heat transfer in a thin nanofluid film on an unsteady stretching surface using homotopy analysis method (HAM), extending the works of Wang (2006) and Xu et al. (2013) to include consideration of the effects of nanofluids and physicallyrealistic value of the Prandtl number of water-based nanofluids, respectively.

\section{Mathematical Models AND Methods}

Wang (2006) considered the fluid flow and heat transfer in a thin Newtonian film of uniform thickness. The fluid motion and heat transfer arise in the stretching of the horizontal elastic sheet. The surface temperature $T_{s}$ of the stretching sheet is assumed to vary with distance and time. The sheet is assumed to move in its own plane with a prescribed velocity $U(x, t)$. Furthermore, the upper free surface of the liquid film, which is in contact with a passive gas, is assumed flat and the effect of surface tension is negligible. The viscous shear stress and the heat flux are assumed to vanish at the adiabatic free surface. In this paper, we extend the model of Wang (2006) to the case of a thin liquid film of a water-based nanofluid containing different type of nanoparticles: $\mathrm{Cu}, \mathrm{Al}_{2} \mathrm{O}_{3}$ and $\mathrm{TiO}_{2}$. The nanofluid is assumed to be incompressible and the flow is assumed to be laminar. It is also assumed that the base fluid (i.e. water) and the nanoparticles are in thermal equilibrium and no slip occurs between them. Under these assumptions and using the nanofluid model proposed by Tiwari and Das (2007), the governing conservation equations of mass, momentum and energy for a nanofluid at unsteady state can be expressed as,

$$
\begin{aligned}
& \frac{\partial u}{\partial x}+\frac{\partial v}{\partial y}=0, \\
& \frac{\partial u}{\partial t}+u \frac{\partial u}{\partial x}+v \frac{\partial u}{\partial y}=\frac{\mu_{n f}}{\rho_{n f}} \frac{\partial^{2} u}{\partial y^{2}}, \\
& \frac{\partial T}{\partial t}+u \frac{\partial T}{\partial x}+v \frac{\partial T}{\partial y}=\alpha_{n f} \frac{\partial^{2} T}{\partial y^{2}},
\end{aligned}
$$

subject to

$$
\begin{array}{ll}
u=U, \quad v=0, \quad T=T_{\mathrm{s}} \quad \text { at } & y=0, \\
\frac{\partial u}{\partial y}=\frac{\partial T}{\partial y}=0, \quad v=\frac{\mathrm{d} h}{\mathrm{~d} t} \quad \text { at } & y=h,
\end{array}
$$

where $u$ and $v$ are the velocity components of the fluid in the horizontal $x$ - and vertical $y$-directions; $T$ is the temperature; $v$ is the kinematic viscosity; $\rho$ is the density; $\kappa$ is the thermal diffusivity and $h(t)$ is the thickness of the liquid film. The velocity of the stretching surface is defined as $U=b x /(1-\alpha t)$, with $\alpha$ and $b$ as positive constants. $\mu_{n f}$ is the effective viscosity and $\rho_{n f}$ is the effective density of the nanofluid which are given by,

$$
\mu_{n f}=\frac{\mu_{f}}{(1-\phi)^{2.5}}, \quad \rho_{n f}=(1-\phi) \rho_{f}+\phi \rho_{s},
$$

where $\phi$ is the nanoparticle volume fraction; $\rho_{f}$ is the reference density of the fluid fraction; $\rho_{s}$ is the reference density of the solid fraction; and $\mu_{f}$ is the viscosity of the fluid fraction. The viscosity of the nanofluid can be approximated as the viscosity of a base fluid $\mu_{f}$ containing the dilute suspension of fine spherical particles; its expression has been given by Brinkman (1952). The thermal diffusivity of a nanofluid is defined as

$$
\alpha_{n f}=\frac{k_{n f}}{\left(\rho C_{p}\right)_{n f}}, \quad \frac{k_{n f}}{k_{f}}=\frac{\left(k_{s}+2 k_{f}\right)-2 \phi\left(k_{f}-k_{s}\right)}{\left(k_{s}+2 k_{f}\right)+\phi\left(k_{f}-k_{s}\right)}
$$

where $k_{n f}$ is the effective thermal conductivity of the nanofluid; $k_{f}$ is the thermal conductivity of the fluid; $k_{s}$ is the thermal conductivity of the solid; and the heat capacitance of the nanofluid is given by

$$
\rho\left(C_{p}\right)_{n f}=(1-\phi)\left(\rho C_{p}\right)_{f}+\phi\left(\rho C_{p}\right)_{s}
$$


The temperature of the elastic sheet is assumed to vary both along the sheet and with time in accordance with,

$$
T_{\mathrm{s}}=T_{\mathrm{o}}-T_{\text {ref }} \frac{b x^{2}}{2 v}(1-\alpha t)^{-3 / 2}
$$

where $T_{\mathrm{o}}$ is the temperature at the slit; $T_{\text {ref }}$ is the constant reference temperature for all $t<1 / \alpha$. The surface of the planar liquid film is assumed to be smooth and free of surface waves, while viscous shear stress and heat flux are assumed to vanish at the adiabatic free surface. We employ the similarity transformations which are given as,

$$
\begin{aligned}
& \psi=\beta x\left[\frac{v_{f} b}{1-\alpha t}\right]^{1 / 2} f(\eta), \\
& T=T_{0}-T_{\text {ref }}\left[\frac{d x^{2}}{v_{f}(1-\alpha t)^{-\frac{3}{2}}}\right] \theta(\eta), \\
& \eta=\frac{1}{\beta}\left[\frac{b}{v_{f}(1-\alpha t)}\right]^{1 / 2} y,
\end{aligned}
$$

where $\beta$ is the dimensionless film thickness; and $\psi(x, y)$ is the stream function defined by,

$$
\begin{aligned}
& u=\frac{\partial \psi}{\partial y}=\frac{b x}{(1-\alpha t)} f^{\prime}(\eta), \\
& v=-\frac{\partial \psi}{\partial x}=-\left(\frac{v b}{1-\alpha t}\right)^{1 / 2} \beta f(\eta),
\end{aligned}
$$

where a prime denotes differentiation with respect to $\eta$. Apparently, (13) and (14) have already satisfied the continuity equation in (1). Consequently, (1) - (5) are transformed to the following nonlinear boundary-value problem:

$$
\begin{aligned}
& \frac{1}{(1-\phi)^{2.5}\left(1-\phi+\phi \frac{\rho_{s}}{\rho_{f}}\right)} f^{\prime \prime \prime}+\gamma\left(f f^{\prime \prime}-\frac{1}{2} S \eta f^{\prime \prime}-\left(f^{\prime}\right)^{2}-S f^{\prime}\right)=0, \\
& \frac{\frac{k_{n f}}{k_{f}}}{\operatorname{Pr}\left(1-\phi+\phi \frac{\left(\rho C_{p}\right)_{s}}{\left(\rho C_{p}\right)_{f}}\right)} \theta^{\prime \prime}+\gamma\left(f \theta^{\prime}-2 f^{\prime} \theta-\frac{1}{2} S \eta \theta^{\prime}-\frac{3}{2} S \theta\right)=0,
\end{aligned}
$$

subject to

$$
f(0)=0, f^{\prime}(0)=1, \theta(0)=1,
$$

$$
f(1)=\frac{1}{2} S, \quad f^{\prime \prime}(1)=0, \quad \theta^{\prime}(1)=0,
$$

where $S=\alpha / b$ is the dimensionless measure of unsteadiness; $\mathrm{Pr}$ is the Prandtl number and the dimensionless film thickness $\gamma=\beta^{2}$ is an unknown constant to be determined.

The most important characteristics of flow and heat transfer are the shear stress $\tau_{s}$ and the heat flux $q_{s}$ on the stretching sheet that are defined as,

$$
\begin{aligned}
& \tau_{\mathrm{s}}=\mu\left(\frac{\partial \mu}{\partial y}\right)_{y=0}, \\
& q_{\mathrm{s}}=-\kappa\left(\frac{\partial T}{\partial y}\right)_{y=0},
\end{aligned}
$$

where $\mu$ is the fluid dynamic viscosity. The local skinfriction coefficient $C_{\mathrm{f}}$, and the local Nusselt number $N u_{x}$ can be defined as,

$$
\begin{aligned}
& C_{\mathrm{f}}=\frac{\tau_{\mathrm{s}}}{\rho_{\mathrm{f}} u^{2} / 2}, \\
& N u_{x}=-\frac{x q_{\mathrm{s}}}{\kappa T_{\text {ref }}} .
\end{aligned}
$$

Thus, the skin friction and the rate of heat transfer for fluid flow in a thin film can be expressed as,

$$
\begin{aligned}
& \frac{1}{2} C_{\mathrm{f}} \operatorname{Re}_{x}^{1 / 2}=\frac{1}{\beta} f^{\prime \prime}(0), \\
& N u_{x} \operatorname{Re}_{x}^{-1 / 2}=\frac{d x^{2}}{\beta v_{\mathrm{f}}(1-\alpha t)^{\frac{1}{2}}} \theta^{\prime}(0),
\end{aligned}
$$

where $\operatorname{Re}_{x}=U x / v_{f}$ is the local Reynolds number.

We apply HAM to solve system (15)-(18). We select the following initial approximations and auxiliary linear operators:

$$
\begin{aligned}
& f_{0}(\eta)=\eta+\frac{3 S-6}{4} \eta^{2}+\frac{2-S}{4} \eta^{3}, \\
& \theta_{0}(\eta)=1, \\
& L_{v}(f)=\frac{\partial^{3}}{\partial \eta^{3}}(\eta), \\
& L_{\theta}(\theta)=\frac{\partial^{2}}{\partial \eta^{2}}(\eta),
\end{aligned}
$$

and the properties satisfied by the auxiliary linear operators are,

$$
\begin{aligned}
& L_{v}\left[C_{1}+C_{2} \eta+C_{3} \eta^{2}\right]=0, \\
& L_{\theta}\left[C_{4}+C_{5} \eta\right]=0,
\end{aligned}
$$


where $C_{1}, C_{2}, C_{3}, C_{4}$ are $C_{5}$ constants of integrations. If $p \in[0,1]$ is an embedding parameter, $\eta_{f}$ and $\eta_{\theta}$ are nonzero auxiliary parameters.

\section{RESULTS AND DISCUSSION}

The analytic solutions of the problem defined by (15) (16) have been computed. The analytic solutions given by HAM contain an auxiliary parameter $\eta$ which could be chosen by means of the $\eta$-curve (Liao 2009, 2004). The solutions in (31) and (32) contain non-zero auxiliary parameters $\eta_{f}$ and $\eta_{\theta}$, which can adjust and control the convergence of the solutions. It is seen from Figure 1 that the convergent results of $\gamma$ can be obtained by choosing a value of $\eta_{f}$ in the range of for as shown in (a), $-1.55 \leq \eta_{f} \leq-0.30$ for $\mathrm{Al}_{2} \mathrm{O}_{3}$ in (b) $-1.60 \leq \eta_{f} \leq-0.30$ and for in (c). The proper value of $\eta_{f}$ for $\mathrm{Cu}$ is in the range of $-1.70 \leq \eta_{f} \leq-0.40$, while that for $\mathrm{Al}_{2} \mathrm{O}_{3}$ is chosen from and $-1.50 \leq \eta_{f} \leq-0.50$ for $-1.40 \leq \eta_{f} \leq-0.50$ for $\mathrm{TiO}_{2}$. The admissible value of $\eta_{\theta}$ for $\mathrm{Cu}$ is $-1.30 \leq \eta_{\theta} \leq-0.20$; for $\mathrm{Al}_{2} \mathrm{O}_{3}$, the proper value is $-1.25 \leq \eta_{\theta} \leq-1.10$, and the proper value of $\eta_{\theta}$ for $\mathrm{TiO}_{2}$ is $-1.20 \leq \eta_{\theta} \leq-1.10$.

Adopting the procedure discussed in Liao (2009), the final solutions is defined as,

$$
\begin{aligned}
& f_{m}(\eta)=\sum_{k=2}^{4 m+3} a_{m, k}(\eta) \eta^{k} \\
& \theta_{m}(\eta)=\sum_{k=1}^{4 m} c_{m, k}(\eta) \eta^{k}
\end{aligned}
$$

for $m \geq 1$, where $a_{m, k}$ and $c_{m, k}$ of $f_{m}(\eta)$ and $\theta_{m}(\eta)$ can be obtained recursively for $m=1,2,3, \ldots$ using

$$
a_{0,1}=1, \quad a_{0,2}=\frac{3 S-6}{4}, a_{0,3}=\frac{2-S}{4}, b_{0,0}=1 \text {, }
$$

given by (39) and (40). For $\mathrm{Cu}$, then when $m=1$ and $\phi=$ 0.05 , we have the following analytic solutions:

$$
f_{1}(\eta)=\sum_{k=2}^{7} a_{1, k}(\eta) \eta^{k}, \theta_{1}(\eta)=\sum_{k=1}^{4} c_{1, k}(\eta) \eta^{k},
$$

where

$$
\begin{aligned}
& a_{1,2}=\frac{9 \hbar_{f}\left(25 S^{3}-94 S^{2}+76 S+24\right)}{40 R}, \\
& a_{1,3}=\frac{-18 \hbar_{f}\left(-11 S^{2}+8 S+4+3 S^{3}\right)}{5 R}, \\
& a_{1,4}=\frac{63 \hbar_{f}(S-2)\left(-4 S+3 S^{2}-4\right)}{32 R}, \\
& a_{1,5}=\frac{-63 \hbar_{f}(S-2)\left(S^{2}+4 S-12\right)}{160 R},
\end{aligned}
$$

$$
\begin{aligned}
& a_{1,6}=\frac{-63 \hbar_{f}(S-2)\left(S^{2}-4 S+4\right)}{160 R}, \\
& a_{1,7}=\frac{9 \hbar_{f}(S-2)\left(S^{2}-4 S+4\right)}{160 R}, \\
& c_{1,1}=\frac{-525 \hbar_{\theta}(S-2)}{4 R}, \\
& c_{1,2}=\frac{105 \hbar_{\theta}(S-2)(4+3 S)}{8 R}, \\
& c_{1,3}=\frac{105 \hbar_{\theta}(S-2)^{2}}{4 R}, \\
& c_{1,4}=\frac{-105 \hbar_{\theta}(S-2)^{2}}{16 R},
\end{aligned}
$$

where $R=11-25 S+36 S^{2}$. The thermophysical properties of fluid (water) and solid $\mathrm{Cu}, \mathrm{Al}_{2} \mathrm{O}_{3}$ and $\mathrm{TiO}_{2}$ phases are tabulated in Table 1. When $\phi=0$ (regular fluid) is considered, the analytic solution will be the same as that presented by Wang (2006). Comparison presented in Table 2 shows that our results are in good agreement with that of Wang (2006). The Prandtl number of the base fluid (water) was kept constant at 6.2. From Table 2, we observe that the value of the skin friction coefficient $f^{\prime \prime}(0)$ for the three types of nanoparticles (water- $\mathrm{Cu}$, water- $\mathrm{Al}_{2} \mathrm{O}_{3}$ and water- $\mathrm{TiO}_{2}$ ) are constant at 1.442625 for different values of solid volume fraction of nanoparticles $\phi$ when $\eta_{f}=-\eta_{\theta}$ and $\eta_{\theta}$ varies for each particle. A lower heat transfer was obtained for the water- $\mathrm{Cu}$. It is also recorded in Table 3 that the heat transfer rate $-\theta^{\prime}(0)$ decreases when the solid volume fraction of nanoparticles $\phi$ increases. This agrees with the observation by Santra (2008) that the heat transfer decreased as the volume fraction of the nanofluid increased.

The effects of solid volume fraction of nanoparticles $\phi$ on the temperature distributions for water- $\mathrm{Cu}$, water$\mathrm{Al}_{2} \mathrm{O}_{3}$ and water- $\mathrm{TiO}_{2}$ are demonstrated in Figure 2. From the figure, we observe that as the $\phi$ increases, temperature distribution increases since the high concentration of solid nanoparticles yields a higher ratio of thermal conductivity. Figure 3(a) presents the temperature distributions $\theta(\eta)$ of water- $\mathrm{Cu}$, water- $\mathrm{Al}_{2} \mathrm{O}_{3}$ and water$\mathrm{TiO}_{2}$ using 10th order HAM approximation with $\phi=0.05$. It is shown that water- $\mathrm{Cu}$ initially has a slightly higher temperature then that of water- $\mathrm{Al}_{2} \mathrm{O}_{3}$ and water- $\mathrm{TiO}{ }_{2}$, but the temperature eventually decreases when $\eta$ increases. It is observed that in Figure 3(b), the velocity profiles of the $\theta(\eta)$ of water- $\mathrm{Cu}$, water- $\mathrm{Al}_{2} \mathrm{O}_{3}$ and water- $\mathrm{TiO}_{2}$ are the same. That is, the nanoparticles volume fraction does not affect the velocity of the fluid flow since the ratio of effective viscosity and effective density of all three types of nanoparticles is very similar. 
(a)

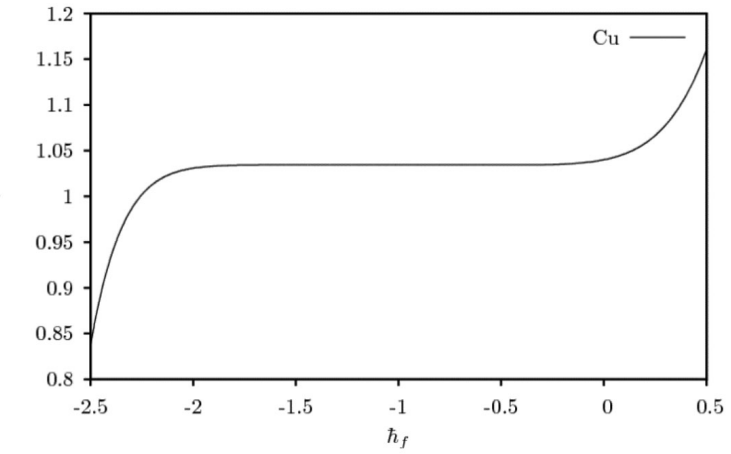

(b)

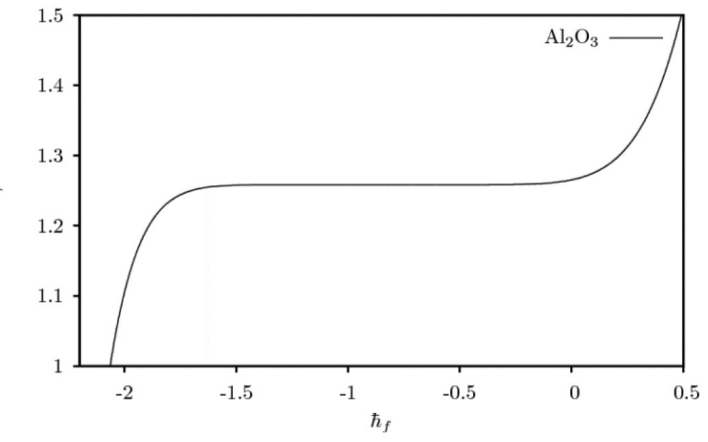

(c)

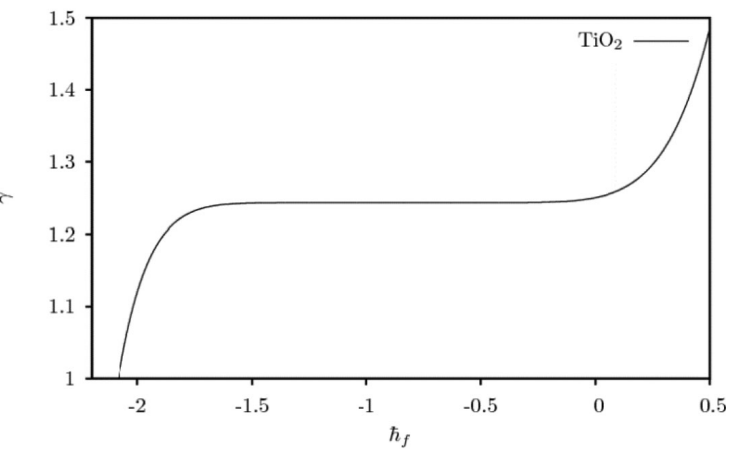

FIGURE 1 . The $\eta_{f}$-curves of $\gamma$ for three nanoparticles (a) $\mathrm{Cu}$, (b) $\mathrm{Al}_{2} \mathrm{O}_{3}$ and (c) $\mathrm{TiO}_{2}$ using 10th-order HAM approximation for the case of $S=1.2, \operatorname{Pr}=6.2$ and $\phi=0.05$

TABLE 1. Thermo-physical properties of water with $\mathrm{Cu}, \mathrm{Al}_{2} \mathrm{O}_{3}$ and $\mathrm{TiO}_{2}$ solid nanoparticles (Abu Nada \& Oztop 2008)

\begin{tabular}{lcccc}
\hline Physical properties & water & $\mathrm{Cu}$ & $\mathrm{Al}_{2} \mathrm{O}_{3}$ & $\mathrm{TiO}_{2}$ \\
\hline$C p(\mathrm{~J} / \mathrm{kgK})$ & 4179 & 385 & 765 & 686.2 \\
$\rho\left(\mathrm{KG} / \mathrm{m}^{3}\right)$ & 997.1 & 8933 & 3970 & 4250 \\
$k(\mathrm{~W} / \mathrm{mK})$ & 0.613 & 400 & 40 & 8.9538 \\
$\alpha \times 10^{7}\left(\mathrm{~m}^{3} / \mathrm{s}\right)$ & 1.47 & 1163.1 & 131.7 & 30.7 \\
\hline
\end{tabular}

TABLE 2. Comparison against the results of Wang (2006) for the case $\phi=0, \operatorname{Pr}=1$

\begin{tabular}{ccccccc}
\hline \multicolumn{3}{c}{ Present work } & \multicolumn{3}{c}{ Wang (2006) } \\
\hline$S$ & $f^{\prime \prime}(0)$ & $\theta(1)$ & $\theta^{\prime}(0)$ & $f^{\prime \prime}(0)$ & $\theta(1)$ & $\theta^{\prime}(0)$ \\
\hline 0.8 & -2.680943 & 0.097956 & 3.591125 & -2.68094 & 0.097884 & 3.595970 \\
1.0 & -1.972384 & 0.266422 & 2.533515 & -1.97238 & - & - \\
1.2 & -1.442625 & 0.286717 & 1.999590 & -1.442631 & 0.286717 & 1.999590 \\
1.4 & -1.012784 & 0.821032 & 1.012784 & -1.012784 & - & - \\
1.6 & -0.642397 & 0.567173 & 0.642397 & -0.642397 & - & - \\
1.8 & -0.309137 & 0.356389 & 0.309137 & -0.309137 & - & - \\
\hline
\end{tabular}



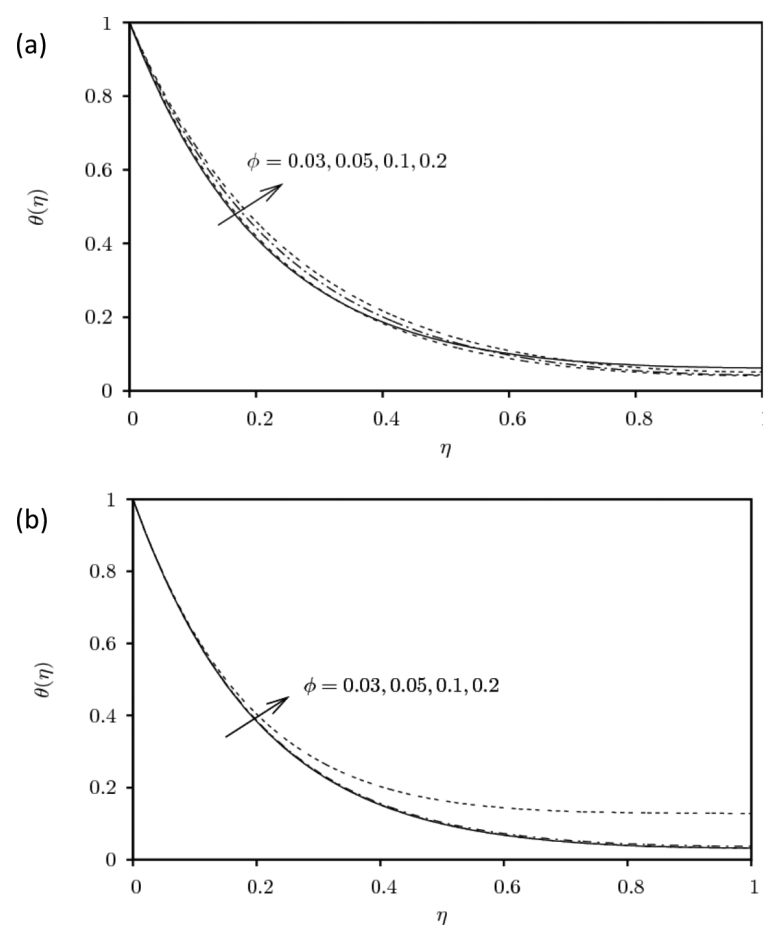

(c)

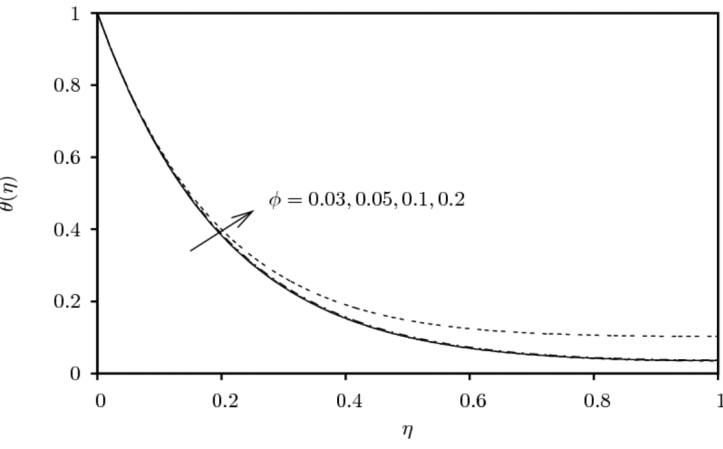

FIGURE 2. The $\eta_{f}$-curve of for three nanoparticles (a) $\mathrm{Cu}$,

(b) $\mathrm{Al}_{2} \mathrm{O}_{3}$ and $\mathrm{TiO}_{2}$ (c) using 10th-order HAM approximation for the case of $S=1.2, \operatorname{Pr}=6.2$ and $\phi=0.05$

\section{CONCLUSION}

The analysis of heat transfer in a thin film on an unsteady stretching sheet in nanofluids has been conducted. The temperature fields as well as the heat transfer rate have been analyzed. The results of the study lead to the following conclusions: the temperature of the fluid increases with the increasing of nanoparticles volume fraction, the heat transfer rate decreases when nanoparticles volume fraction increases and the presence of the nanoparticles in the fluids enhances the heat transfer characteristics.

\section{REFERENCES}

Abel, M.S., Tawade, J. \& Nandeppanavar, M.M. 2009. Effect of non-uniform heat source on MHD heat transfer in a liquid film over an unsteady stretching sheet. International Journal of Non-Linear Mechanics 44(9): 990-998.

Abu-Nada, E. \& Oztop, H.F. 2009. Effects of inclination angle on natural convection in enclosures filled with $\mathrm{Cu}$-water (a)
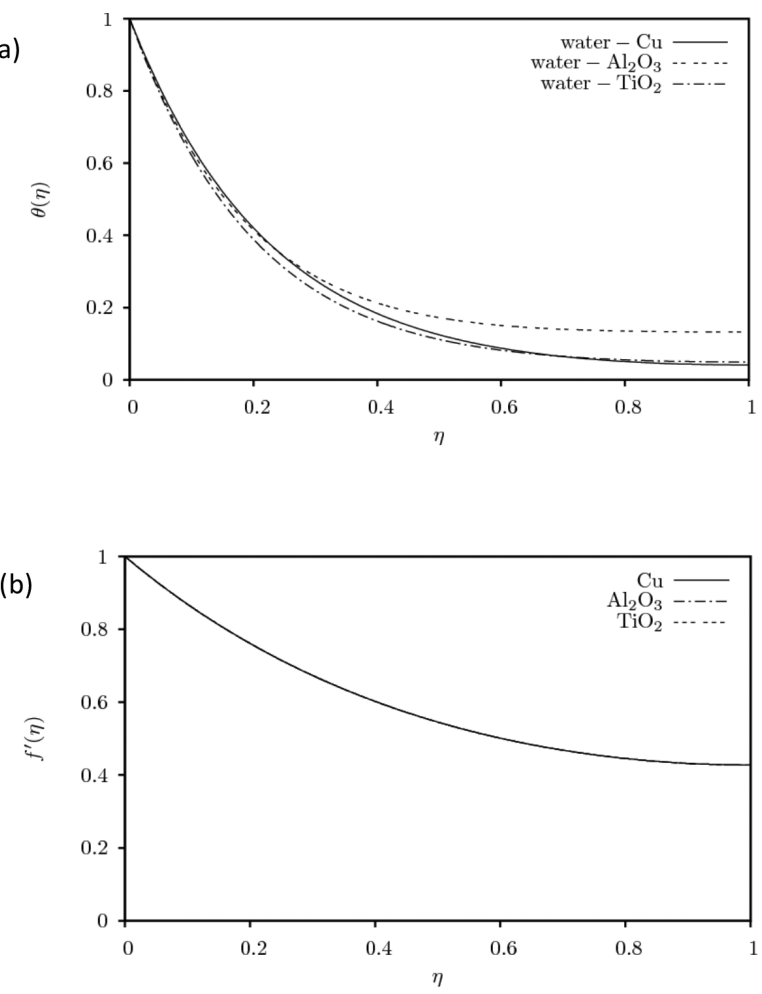

FIGURE 3. (a) The temperature distributions $\theta(\eta)$ and (b) the velocity distribution $f^{\prime}(\eta)$ of water- $\mathrm{Cu}$, water- $\mathrm{Al}_{2} \mathrm{O}_{3}$ and water- $\mathrm{TiO}_{2}$ using 10th-order HAM approximation for

$$
S=1.2, \operatorname{Pr}=6.2, \phi=0.05
$$

TABLE 3 . The values of $f^{\prime \prime}(0)$ and $-\theta^{\prime}(0)$ using 10th-order HAM approximation for different values of solid volume fraction of nanoparticles $\phi$ for $\mathrm{Cu}, \mathrm{Al}_{2} \mathrm{O}_{3}$ and $\mathrm{TiO}_{2}$ when $S=1.2$

\begin{tabular}{|c|c|c|}
\hline \multicolumn{3}{|c|}{$\mathrm{Cu}, \eta_{f}=-1.00, \eta_{\theta}=-1.22$} \\
\hline$\phi$ & $f^{\prime \prime}(0)$ & $-\theta^{\prime}(0)$ \\
\hline 0.03 & -1.442625 & 4.494462 \\
\hline 0.05 & -1.442625 & 4.369323 \\
\hline 0.10 & -1.442625 & 4.107375 \\
\hline 0.20 & -1.442625 & 3.922480 \\
\hline \multicolumn{3}{|c|}{$\mathrm{Al}_{2} \mathrm{O}_{3}, \eta_{f}=-1.00, \eta_{\theta}=-1.15$} \\
\hline$\phi$ & $f^{\prime \prime}(0)$ & $-\theta^{\prime}(0)$ \\
\hline 0.03 & -1.442625 & 4.670536 \\
\hline 0.05 & -1.442625 & 4.657742 \\
\hline 0.10 & -1.442625 & 4.599265 \\
\hline 0.20 & -1.442625 & 3.644218 \\
\hline \multicolumn{3}{|c|}{$\mathrm{TiO}_{2}, \eta_{f}=-1.00, \eta_{\theta}=-1.10$} \\
\hline$\phi$ & $f^{\prime \prime}(0)$ & $-\theta^{\prime}(0)$ \\
\hline 0.03 & -1.442625 & 4.796196 \\
\hline 0.05 & -1.442625 & 4.774650 \\
\hline 0.10 & -1.442625 & 4.747141 \\
\hline 0.20 & -1.442625 & 4.662720 \\
\hline
\end{tabular}


nanofluid. International Journal of Heat and Fluid Flow 30(4): 669-678.

Andersson, H.I., Aarseth, J.B. \& Dandapat, B.S. 2000. Heat transfer in a liquid film on an unsteady stretching surface. International Journal of Heat and Mass Transfer 43(1): 69-74.

Aziz, R.C. \& Hashim, I. 2010. Liquid film on unsteady stretching sheet with general surface temperature and viscous dissipation. Chinese Physics Letters 27(11): 110202.

Aziz, R.C., Hashim, I. \& Abbasbandy, S. 2012. Effects of thermocapillarity and thermal radiation on flow and heat transfer in a thin liquid film on an unsteady stretching sheet. Mathematical Problem Engineering 2012: 127320

Aziz, R.C., Hashim, I. \& Alomari, A.K. 2011. Thin film flow and heat transfer on an unsteady stretching sheet with internal heating. Meccanica 46(2): 349-357.

Brinkman, H.C. 1952. The viscosity of concentrated suspensions and solutions. The Journal of Chemial Physics 20: 571-581.

Choi, S.U.S. 1995. Enhancing thermal conductivity of fluids with nanoparticles. The Proceeding of the 1995 ASME International Mechanical Engineering Congress and Exposition, San Francisco, USA, ASME, FED 231/MD 66: 99-105.

Dandapat, B.S., Singh, S.K. \& Maity, S. 2017. Thin film flow of bi-viscosity fluid over an unsteady stretching sheet: An analytical solution. International Journal Mechanical Sciences 130: 367-374.

Hayat, T.,Ambreen, S., Awais, M.\& Mesloub, S. 2012. Soret and Dufour effects for three-dimensional flow in a viscoelastic fluid over a stretching surface. International Journal of Heat and Mass Transfer 55: 2129-2136.

Liao, S.J. 2004. Beyond Perturbation: Introduction to the Homotopy Analysis Method. Boca Raton: Chapman \& Hall. p. 31.

Liao, S.J. 2004. On the homotopy analysis method for nonlinear problems. Applied Mathematics and Computation 147: 449-513.

Liao, S.J. 2009. Notes on the homotopy analysis method: Some definitions and theorems. Communications in Nonlinear Science and Numerical Simulation 14: 983-997.

Liu, I.C. \& Andersson, H.I. 2008. Heat transfer in a liquid film on an unsteady stretching sheet. International Journal of Thermal Sciences 47(6): 766-772.

Maiga, S.E.B., Palm, S.J., Nguyen, C.T., Roy, G. \& Galanis, N. 2005. Heat transfer enhancement by using nanofluids in forced convection flows. International Journal of Heat and Fluid Flow 26(4): 530-546.

Maity, S., Ghatani, Y. \& Dandapat, B.S. 2016. Thermocapillary flow of a thin nanoliquid film over an unsteady stretching sheet. Journal Heat Transfer 138(4): 042401.

Megahed, A.M. 2015. Effect of slip velocity on Casson thin film flow and heat transfer due to unsteady stretching sheet in presence of variable heat flux and viscous dissipation. Applied Mathematics and Mechanics 36(10): 1273-1284.

Narayana, M. \& Sibanda, P. 2012. Laminar flow of nanoliquid film over an unsteady stretching sheet. International Journal of Heat and Mass Transfer 55(25-26): 7552-7560.

Noor, N.F.M. \& Hashim, I. 2010. Thermocapillarity and magnetic field effects in a thin liquid film on an unsteady stretching surface. International Journal of Heat and Mass Transfer 53(9-10): 2044-2051.
Noor, N.F.M., Abdulaziz, O. \& Hashim, I. 2010. MHD flow and heat transfer in a thin liquid film on an unsteady stretching sheet by the homotopy analysis method. International Journal Numerical Methods in Fluids 63(3): 357-373.

Oztop, H.F. \& Abu-Nada, E. 2008. Numerical study of natural convection in partially heated rectangular enclosures filled with nanofluids. International Journal Heat Fluid Flow 29(5): 1326-1336.

Santra, A.K., Sen, S. \& Chakraborty, N. 2008. Study of heat transfer characteristics of copper-water nanofluid in a differentially heated square cavity with different viscosity models. Journal of Enhanced Heat Transfer 15: 273-287.

Tiwari, R.J. \& Das, M.K. 2007. Heat transfer augmentation in a two-sided lid-driven differentially heated square cavity utilizing nanofluids. International Journal Heat and Mass Transfer 50: 2002-2018.

Vajravelu, K., Prasad, K.V.\& Ng, C.O. 2012. Unsteady flow and heat transfer in a thin film of Ostwald-de Waele liquid over a stretching surface. Communication Nonlinear Science and Numerical Simulation 17(11): 4163-4173.

Waheed, S.E. 2016. Flow and heat transfer in a Maxwell liquid film over an unsteady stretching sheet in a porous medium with radiation. SpringerPlus 5(1): 1061.

Wang, C. 2006. Analytic solutions for a liquid film on an unsteady stretching surface. Heat and Mass Transfer 42: 759-766.

Wang, C.Y. 1990. Liquid film on an unsteady stretching surface. Quarterly of Applied Mathematics 48: 601-610.

Xu, H., Pop, I. \& You, X.C. 2013. Flow and heat transfer in a nano-liquid film over an unsteady stretching surface. International Journal Heat and Mass Transfer 60(1): 646652.

\section{R.C. Aziz}

Faculty of Science \& Technology

Open University Malaysia

50480 Kuala Lumpur, Federal Territory

Malaysia

\section{Hashim*}

School of Mathematical Sciences

Faculty of Science \& Technology

Universiti Kebangsaan Malaysia

43600 UKM Bangi, Selangor Darul Ehsan

Malaysia

S. Abbasbandy

Department of Mathematics

Imam Khomeini International University

Ghazvin 34149-16818

Iran

*Corresponding author; email: ishak_h@ukm.edu.my

Received: 11 September 2017

Accepted: 27 February 2018 